Portland State University

PDXScholar

Environmental Science and Management

Faculty Publications and Presentations

4-2016

\title{
Bridge Over Troubled Waters: A Synthesis Session to Connect Scientific and Decision Making Sectors
}

\author{
Kaitlin Goldsmith \\ Portland State University \\ Elise F. Granek \\ Portland State University, graneke@pdx.edu \\ Amy Lubitow \\ Portland State University, alubitow@pdx.edu \\ Michael Papenfus \\ USEPA
}

Follow this and additional works at: https://pdxscholar.library.pdx.edu/esm_fac

Part of the Environmental Sciences Commons, and the Marine Biology Commons Let us know how access to this document benefits you.

\section{Citation Details}

Goldsmith, K., Granek, E., Lubitow, A., \& Papenfus, M. (2016). Bridge over troubled waters: A synthesis session to connect scientific and decision making sectors. Marine Policy, 70, 30-39. http://doi.org/ 10.1016/j.marpol.2016.04.015

This Article is brought to you for free and open access. It has been accepted for inclusion in Environmental Science and Management Faculty Publications and Presentations by an authorized administrator of PDXScholar. Please contact us if we can make this document more accessible: pdxscholar@pdx.edu. 


\title{
Bridge over troubled waters: A synthesis session to connect scientific and decision making sectors
}

\author{
Kaitlin Goldsmith ${ }^{\mathrm{a}, *}$, Elise Granek ${ }^{\mathrm{a}}$, Amy Lubitow ${ }^{\mathrm{b}}$, Michael Papenfus ${ }^{\mathrm{c}}$ \\ a Environmental Science \& Management, Portland State University, PO Box 751, Portland, OR 97207, United States \\ ${ }^{\mathrm{b}}$ Sociology, Portland State University, PO Box 751, Portland, OR 97207, United States \\ ${ }^{c}$ US EPA, Office of Research and Development, Western Ecology Division, Corvallis, OR 97330, United States
}

\section{A R T I C L E I N F O}

\section{Article history:}

Received 11 January 2016

Received in revised form

20 March 2016

Accepted 10 April 2016

Available online 25 April 2016

\section{Keywords:}

Coastal management

Evidence-based decisions

Research based policy

Stakeholder engagement

Synthesis session

Workshop

\begin{abstract}
A B S T R A C T
Lack of access to relevant scientific data has limited decision makers from incorporating scientific information into their management and policy schemes. Yet, there is increasing interest among decision makers and scientists to integrate coastal and marine science into the policy and management process. Strategies designed to build communication between decision makers and scientists can be an effective means to disseminate and/or generate policy relevant scientific information. Here researchers develop, test, and present a workshop model designed to bridge the gap between coastal and marine decision makers and scientists. Researchers identify successful components of such a workshop as well as areas for improvement and recommendations to design and conduct similar workshops in the future. This novel workshop format can be used in other fora to effectively connect decision makers and scientists, and to initiate an iterative process to generate and transfer policy relevant scientific information into evidence-based decisions, an important element in protecting coastal and marine resources.
\end{abstract}

(c) 2016 Elsevier Ltd. All rights reserved.

\section{Introduction}

When decision makers are involved in defining scientific research project goals there is an increased likelihood of uptake and use of the research findings in policy and management decisions $[6,13,15]$. However, the majority of research planning, design, and execution occur outside of and in isolation from the decision making realm [21]. There is a lack of dialogue between decision makers and scientists, resulting in the currently inadequate use of research findings in decisions [23]. Yet, there is increasing recognition by both decision makers and scientists of the need for more effective inter-sectoral communication and knowledge transfer [16,19]. Promoting tools that enhance the use of scientific data in decision making processes, i.e., devices or mechanisms that promote sharing of information, will enhance society's ability to address pressing problems including, but not limited to, marine and coastal environment issues [21]. However, despite the widely recognized benefits of evidence-based decision making [3], producing and disseminating science that informs decisions remains a challenge [2]. One tool is to raise awareness among researchers of the scientific data needs of decision makers [13]. A second tool is to connect academic or agency scientists that work on

\footnotetext{
*Correspondence to: Permanent address: Environmental Science \& Management, Portland State University, PO Box 751, Portland, OR 97207, United States.

E-mail address: kaitygoldsmith@gmail.com (K. Goldsmith).
}

particular issues with decision makers with relevant data needs $[2,13]$. Using interpersonal strategies that bring decision makers and academic scientists together to transmit knowledge and define more specific goals and projects may lead to more integrated scientific research $[2,19]$.

In-person interactions provide decision makers and scientists the opportunity to connect and relate to each other [10,19]. Davis et al. [4] found that workshops in which face-to-face interactions connected natural resource scientists and decision makers provide an important opportunity for meaningful dialogue. Workshops can provide the opportunity (1) for decision makers to express to scientists the types of information they need and (2) to inform decision makers of scientific advances [16]. Thus, an approach that first identifies and communicates data gaps and then connects decision makers and researchers may be the most effective strategy to generate evidence-based policy and management practices [13]. Using this approach, the researcher team planned, tested, and reflect upon a novel method for establishing this connection. The team designed and conducted a "synthesis session" (SS) - a workshop to build communication between decision makers and researchers based on previously identified data gaps [8]. The researchers suggest that the SS functions as an appropriate networking opportunity [12], a means of increasing knowledge of data gaps among the scientific community, as a tool for improving communication between relevant researchers and decision makers [16], and a means to foster relationships and connections. 
This approach can ultimately lead to increased scientific data use in policy and management [13], and thus enhance the effectiveness of policy and management schemes [7].

In this paper the research team has developed and presents a model for increasing collaboration between scientists and decision makers to promote evidence based decisions. Successes and areas for improvement in the tested model are discussed. This novel workshop model is intended to build and sustain connections, with the ultimate goal of creating better policy and management practices. In a recent study, $89 \%$ of decision makers in the Pacific Northwest thought that outreach programs to decision makers were needed to inform policy and management decisions regarding climate change impacts [14]. Thus, the model presented here is one possible tool for bridging data gaps through increasing connections and fostering communication between siloed sectors that often lack interaction and communication. Research conducted by Davis et al. [4] revealed that similar models of interaction with fire science researchers and managers increased the efficient use of limited time and resources by preventing duplicative research and streamlining data collecting efforts. The SS presented here also sought to identify the utility of ecosystem services as a framework for cross-sector communication; differences in defining ecosystem services made this objective difficult to achieve. This synthesis session model can be applied in other case studies to promote more effective creation and completion of scientific studies geared towards specific policy and management questions to improve ocean and coastal health.

\section{Coastal and marine ecosystem services synthesis session: a case study}

\subsection{Synthesis session background}

The SS was preceded by an interviewing phase in which 26 decision makers ${ }^{1}$ identified marine and coastal data gaps and the types of communication with researchers that were perceived as most effective. Decision makers for the interviewing phase were key coastal and ocean decision makers in state, local, and federal agencies and NGOs as identified by the research team and other researchers whom are knowledgeable about and engaged in the topic (see Goldsmith et al., 2015 [8] for details on interviewing phase). This interviewing phase also sought to determine the ecosystem services most important to decision makers [8], as using ecosystem services in management decisions can balance competing interests and determine best practices for natural resource management [24]. Research has shown that designing a workshop around current issues and concerns generates enthusiasm from participants [18]. Thus, this initial interviewing process was used to conduct the SS in a more efficient manner with data gaps and other pertinent information being shared prior to convening the SS (see Goldsmith et al., 2015 [8] for open ended interview questions). A pre-event data gap identification period is important for the model presented here, though this could take the form of a mail, email or online survey given time and/or monetary constraints. That being said, interviews are the optimal method for this type of need/gap assessment as they provide rich detail and prevent self-selection survey bias [5].

The interviews revealed that formal partnerships and informal networks with knowledgeable individuals were beneficial means of increasing scientific data use in natural resource management

\footnotetext{
${ }^{1}$ Here "decision maker" refers to those individuals actively involved in designing and/or implementing legislative policy, procedures and protocols, and management programs. For more information regarding decision maker selection see Ref. [8].
}

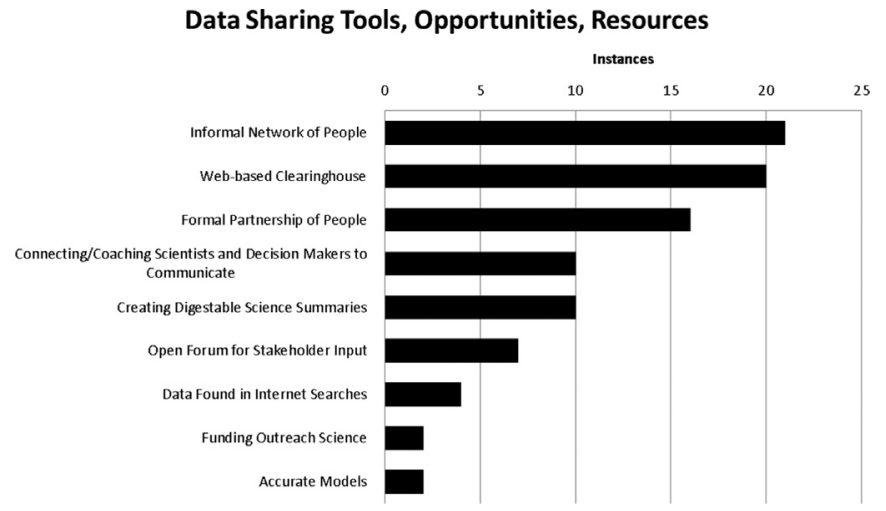

Fig. 1. Tools, opportunities, and resources decision makers identified as fostering increased use of scientific data in decision making [8].

decision making [Fig. 1]. The SS was designed in response to these findings. SS participants included both scientific researchers and decision makers. SS participants were presented the analyzed results of the interviews [8] including tools, opportunities and resources for data sharing [Fig. 1], challenges for decision makers working with scientists [Fig. 2], and priority data gaps. The SS agenda [Appendix A] was based on these results with a focus on building connections and identifying additional tools and opportunities to increase scientific data use in policy and management.

Interview findings determined that by bringing decision makers into the research project design phase, the results could speak more directly to the existing decision maker data needs, while still meeting the goals of the researcher [Fig. 2]. Thus, the SS was designed to directly address this finding. Furthermore, language barriers due to scientific terminology and a lack of communication about existing research findings were identified as barriers to using research in decision making [Fig. 2], thus the SS aimed to address these challenges.

The SS design aims to engage stakeholders from the beginning of the research process to increase 'buy-in' of the end products $[6,17]$. In turn, an improved understanding of decision maker needs can promote more relevant research that directly addresses those needs [17]. When research directly fulfills decision makers' needs, it is more likely to be used in policy [6] and can result in better policy enactment based on the best available science [17]. Research has recognized that cross-sector knowledge production between decision makers and scientists can be an important element in more reflective and deliberative natural resource management [20]. Thus, the SS was designed to establish mutually beneficial connections between decision makers and scientific researchers to eventually increase the creation and use of policy and management relevant research [6].

\section{Decision Makers' Perspective: Barriers to Working With Scientists}

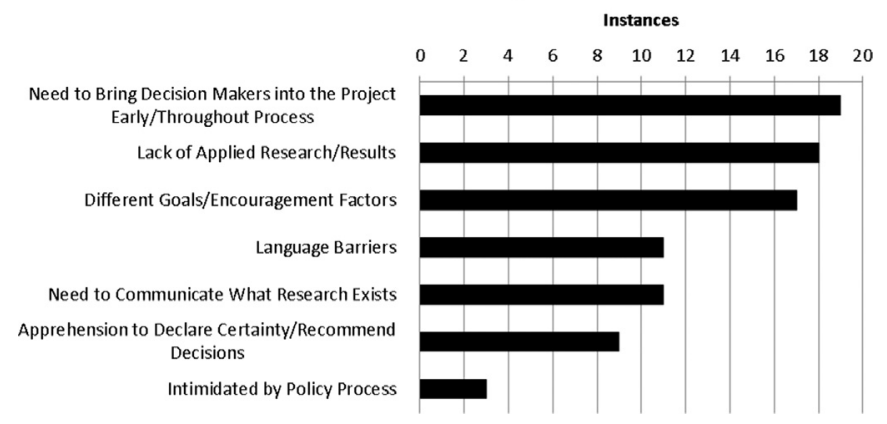

Fig. 2. Decision makers' barriers in working with scientists to increase the use of scientific data [8]. 


\section{Methods and results}

\subsection{Synthesis session creation}

A total of 32 ocean and coastal decision makers from 28 agencies and organizations were invited to the event. Decision makers invited to the event included those involved in the interviewing process [8] as well as practitioners recommended by interviewees. All scientists involved in coastal and marine research relevant to the scientific data gaps and ecosystem service priorities identified during previous interviews [8], 40 in total, were invited from regional academic institutions, including Portland State University, Washington State University Vancouver, University of Oregon, and Oregon State University as well as university affiliated research organizations. Invitees were told that the event would include decision makers and academic researchers taking part "in a series of presentations and interactive sessions intended to develop collaborative strategies to move forward on filling [the] data gaps (i.e. those gaps identified during the interviewing phase)". Invitees were told that the goal of the event was to "facilitate scientific-based decision-making about Oregon's coasts and oceans" and to "foster connections between and among scientists and decision makers to begin the development of projects directly related to pressing decisions". The event took place at a hotel in Corvallis, OR based on its central location to invitees coming from north and south, inland and the coast, and as a neutral site between sectors. Twenty-two individuals, 10 scientists and 12 decision makers, participated in the half-day session held from $10 \mathrm{am}$ to $3 \mathrm{pm}$.

Three weeks prior to the workshop, participants were asked to prepare 3-5 min mini-presentations on either: (1) a policy or management project on which the participant was working that lacked sufficient scientific data or (2) ongoing or future research that related to policy and management in coastal/nearshore Oregon ecosystems. To assist in framing these mini-presentations, the following action-oriented goals for the event were listed: (1) communicate current data needs, (2) encourage cooperation between sectors (researchers and decision makers) to design research projects (e.g., ecosystem services related data needs), and (3) generate a commitment to follow up with at least one attendee regarding potential projects. Participants were offered the opportunity to provide PowerPoint presentations, with a maximum of 4 slides, prior to the event.

Upon arrival, participants completed a standard pre-event survey designed to identify participants' expectations for the day [19] [Appendix B]. The workshop began with brief introductions that included each participant's name, organizational affiliation, and favorite marine organism. Attendees shared their favorite marine animal as a mini ice-breaker to open dialogue with a simple insight about each attendee. After a brief overview of the agenda, the research team presented on the ecosystem services priorities and scientific data needs identified through the interviews conducted in 2013 [8]. Then each participant gave a minipresentation. During lunch, a discussion on "Opening Lines of Communication" took place to enhance free flowing communication between the two sectors. Participants were encouraged to discuss barriers and difficulties in communicating with each other as well as opportunities to overcome barriers to enhance collaborative work. Participants were then provided the opportunity to work through these barriers and identify points of collaboration through a "speed dating" activity. During this exercise, individuals from different sectors were provided the opportunity to communicate one-on-one during five rotations. Scientists remained seated while decision makers rotated, selecting a scientist whose research they considered most akin to their decision making needs (based on the mini-presentations). This activity allowed participants to have 5 mini-conversations for $8 \mathrm{~min}$ each. Since there were more decision makers than scientists, some 'one-onone' discussions included three individuals. Participants were encouraged to ask questions that arose from mini-presentations and to discuss possible research projects that addressed the needs/ interests of both individuals. After establishing these connections, participants were provided the opportunity to discuss, as a group, how to best sustain them. This discussion, titled "Sustaining Connections" focused on best strategies for following-up and creating projects with other participants. Finally, a brief wrap-up had participants reflect on the event by answering three questions on a quarter sheet piece of paper:

1) With whom will you follow-up (other attendee[s])?

2) When will you follow-up with this person?

3) What project(s) have you both discussed pursuing?

Participants then put the paper in a self-addressed envelope (provided). These envelopes were mailed one month post-event as a reminder to participants to follow-up and sustain the connections they made during the workshop. After a brief thank you, the participants were asked to complete a post-event survey [Appendix C] to evaluate the successes as well as opportunities for improving future workshops of this nature.

Eight months following the SS, participants received a brief email asking 2 questions regarding their continued interactions with SS participants [Appendix D]. These questions were intended to gauge the longevity of connections made during the SS.

The synthesis session presented here provides a workshop format that opened lines of communication between the scientists and decision makers in attendance to foster dialogue for evidence based decision making. Seventy-two individuals were invited, representing 40 scientists and 32 decision makers, 14 scientists (35\%) and 15 decision makers (47\%) accepted the invite (40\% of all invites), and due to some attrition resulting from coinciding events, 22 (31\% of all invitees) were in attendance, 12 scientists (30\%) and 10 decision makers (31\%). The SS format was selected to build on previous successes of mini-presentations and speed dating from scientific society conferences [11] and to test its effectiveness in a venue aimed at linking scientists and decision makers.

\subsection{Meeting workshop goals and attendee expectations}

In the pre-event survey, a question was asked regarding attendee expectations for the day. In this multiple choice question, the research team's workshop goals were offered as options, from which attendees could select as many or as few as they wanted [Fig. 3]. Expectations for the day were high, with every multiple choice option, with the exception of "other", selected by more than half the participants. The lowest among these, "personal connections to decision makers", was selected by $59 \%$ of participants. Primarily participants expected to "develop new collaborations" during the event ( $82 \%$ of participants). In post-surveys at least $65 \%$ of participants said they developed new collaborations. Roughly $77 \%$ of participants wanted to learn more about pressing marine and coastal data needs during the workshop. Post-event surveys revealed that almost $60 \%$ of participants felt better informed about these pressing marine and coastal data needs.

Participants' overall experience was assessed in the post-event survey through a multiple choice question based on workshop goals. Respondents could select multiple responses to indicate success of the SS in addressing workshop goals [Fig. 3]. "Developed a new collaboration or connection" was the most significant experience from the day for the majority of respondents $(65 \%$; [Fig. 3]). "Learned more about pressing marine and coastal data 


\section{Pre and Post Event Expectations and Outcomes}

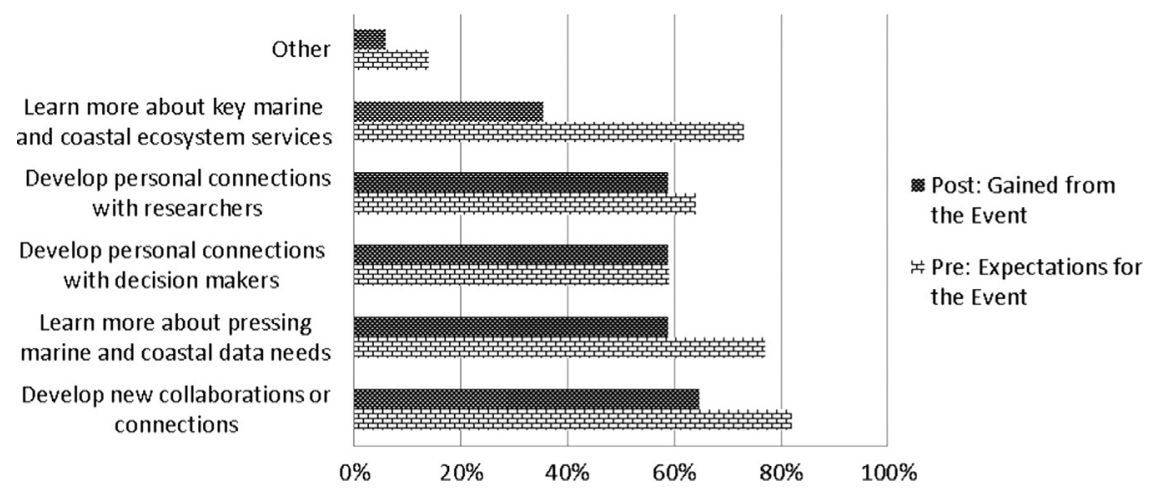

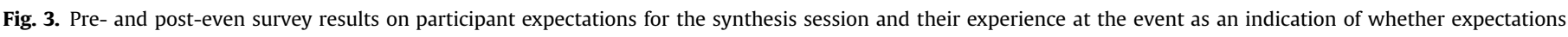
were met.

needs", "made personal connections with decision makers", and "made personal connections with researchers" were selected second most frequently (59\% of respondents; [Fig. 3]). "Learned more about key marine and coastal ecosystem services" was chosen least frequently (35\% of participants; [Fig. 3]). One individual selected the "other" option, and noted that s/he "had [the] opportunity to present research/data needs to colleagues". The high response rate to four of the five outcomes indicates that the majority of participant expectations were met through the format and activities conducted during the SS.

Comparisons of pre- and post-event surveys reveal that most workshop expectations were well addressed by the activities conducted, with one notable exception. The workshop failed to provide adequate activities for participants to learn about key marine and coastal ecosystem services. While $73 \%$ of participants were expecting to learn more about key ecosystem services during the workshop, only 35\% felt they had [Fig. 3]. However, it is clear that most participants viewed networking as their most important goal. A day full of presentations learning about ecosystem services would have interfered with that goal; however a workshop session with active learning on the topic that allowed for networking and learning, may be the optimal approach.

\subsection{Building connections}

In pre-event surveys, participants expressed that communication, collaboration, common goals, sharing information, and having common interests were characteristics of a successful professional connection. Since the day's activities revolved around enhancing these characteristics, the SS was able to address the underlying features of forming successful collaborations. Thus, the new collaborations that participants made during the day are grounded in identified characteristics of successful collaboration.

Furthermore, in post-event surveys participants were asked to report on the number of professionals they intended to follow-up with post-synthesis session. They stated between 1 and 6 [Fig. 4] with some participants stating a range, in this case their answers were recorded in the lower number categories. For example a participant that stated "5-6" was marked as answering 5 connections, thus erring on the side of underrepresenting the number of connections resulting from the SS. Two was the most commonly stated response with $35 \%$ of participants stating they would follow-up with 2 connections, closely followed by 3 connections (29\% of participants; [Fig. 4]). Thus, this event, intended to build connections, was able to establish these links.

Follow up conducted via email 8 months after the SS demonstrated that some people had maintained connections. For

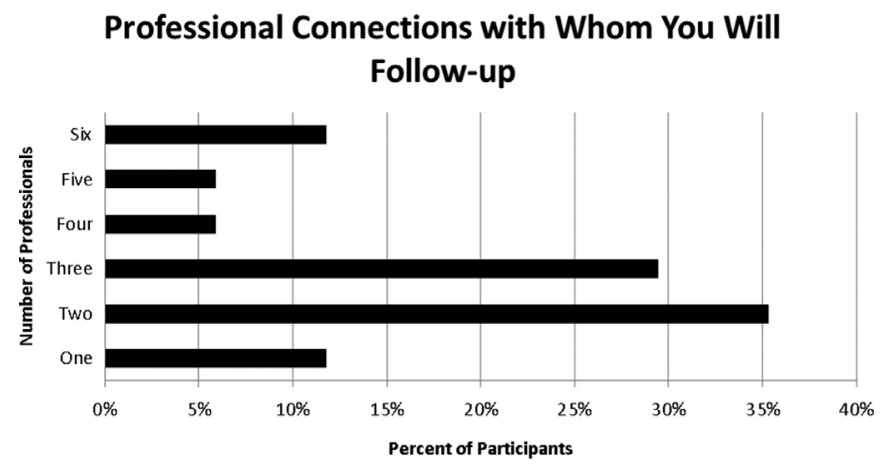

Fig. 4. The number of professional connections with whom participants intend to follow-up.

example, one respondent reported that there has been post-SS "cooperation on coastal zone water quality strategies" with another SS attendee. However, other informal email responses revealed that the connections were not sustained months after the SS. Thus, organizing subsequent workshops would be beneficial to reinforce connections and build sustained relationships, though more research is needed to understand what format is best for achieving the desired long-term relationships. None-the-less, during follow-up communication, one participant emphasized that meeting in person at the SS allowed for ease of communication between all participants when the time arises and not to underestimate the worth of that. Furthermore, during the interviewing phase, sustained engagement through research projects was indicated as important for bridging the gap between decision makers and scientists [Fig. 2].

\subsection{Activity success}

The post-event survey asked participants to rank their top 3 activities, which provided insights into which activities were most important in achieving the day's goals. Some respondents included benefits such as "feeling like my training and research questions matter". Responses that refer to benefits, rather than activities, have been noted as "other".

The mini-presentations offered by all participants were the most popular activity of the day [Fig. 5]. Participants were able to communicate their research and policy interests, as well as learn about those of other professionals in the room. This meant that even for attendees unable to stay for the afternoon, they were more aware of who they could contact regarding particular issues moving forward. 


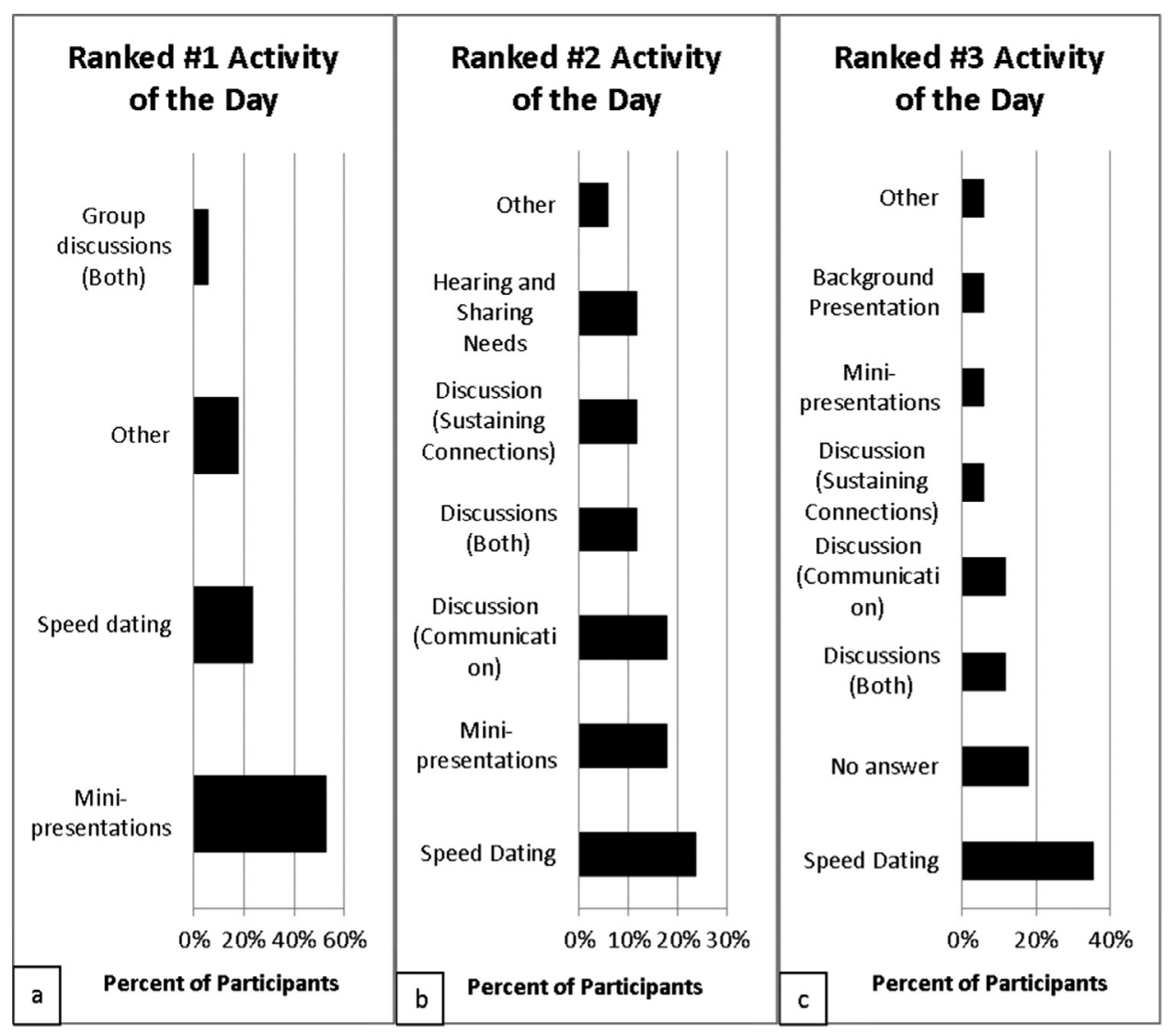

Fig. 5. Rank of workshop activities; Activities ranked: a. number 1; b. number 2; and c. number 3.

Speed dating was the second most successful activity of the day allowing participants to begin communicating with those individuals who expressed shared interests during mini-presentations, thereby providing the opportunity to broaden participant networks. The importance of broadening networks reflects back to the interview results [Fig. 1] that show formal and informal interactions and communications between the decision making and scientific sectors as an important tool to increase use of research in decision making. The discussion titled "Opening Lines of Communication" was the third most beneficial activity of the day, and certainly began to break down the barriers in communication between sectors.

\section{Recommendations for future synthesis sessions}

\subsection{Content}

Participant evaluations and organizer observations offer important recommendations to improve similar workshops in the future. First, the agenda lacked one key element. A discussion to learn about key marine ecosystem services [8] would have facilitated shared understanding and better achieved the goal of eliminating language barriers between sectors [Fig. 2]. Given that decision makers interpret ecosystem services differently (i.e., categorizing them into the pillars of sustainability) [8] than scientists (many of whom use the Millennium Ecosystem Assessment categories or a variation thereof), a discussion could have helped participants be on the same page. Specifically, on the post-event survey, one participant suggested that ecosystem services were not well defined by the group. Discussing ecosystem services definitions would have facilitated translation and communication of knowledge between decision makers and scientists [2] and would have helped researchers determine if an ecosystem services framework is appropriate to bridge the gap between these two sectors. Additional research is needed to further explore the possibility of using ecosystem services as a common language to bridge communication between the scientific and decision making sectors [9].

The "Opening Lines of Communication" session was rated as the third most successful exercise of the day, generating ample discussion and reflection. At the start of the discussion participants were shown Fig. 2 and asked to reflect on either (1) what challenges the scientific community has in working with decision makers and/or (2) ways to work through and overcome these challenges or existing barriers. As the discussion evolved, it focused predominantly on this second point of overcoming the barriers expressed by decision makers. One participant noted in their post-event survey that there should have been an opportunity for scientists to provide a reflection on their perspective of barriers. Thus, a future approach would be to split this discussion into two parts, one for each discussion point, allowing for a fuller discussion to emerge. The focus for the second discussion, overcoming barriers, should be provided a longer timeframe as this is a critical piece. The groups should be provided a sufficient opportunity to develop solutions that are in their common interests.

The discussion titled "Sustaining Connections" ended the day with an individual commitment from each participant to list with whom they would follow-up; a statement about what projects had been discussed with those participants, and a timeline for followup. In addition to this commitment, however, an additional piece of the process that could facilitate sustained networking would be to ask each group to suggest possible means of sustaining the connection. While the group's suggestions should be considered and pursued, it is important to note that simply identifying mechanisms for continued communication does not confirm that 
participants will use them. Additional research on maintaining these connections is needed. Furthermore, time should have been devoted to reflecting on what had been accomplished throughout the day [18] to solidify the success of such interactions and reinforce the value of the time involved. These changes to content would have enhanced the SS wrap up.

\subsection{Logistics}

Potential modifications to the timing, including adding $2-3 \mathrm{~h}$ to make the SS a full day, would accommodate the previously mentioned recommended improvements to the workshop's content. When asked to recommend activities to add to similar events in the future, 8 of the 14 participants who answered this question suggested more time for either a particular activity conducted or the day in general. During planning, SS facilitators should choose a date that avoids holidays and other known conferences and workshops. Before finalizing the event date, potential participants should be polled to best avoid scheduling conflicts.

Finally, the space for an SS should be intimate with tables arranged in a horseshoe design to create an atmosphere that fosters honest and robust group discussion [11]. During the speed-dating session, decision makers and scientists sat on either side of the tables still arranged in a horseshoe design. The SS should also take place at a locale mid-point among attendees to ease transportation burden. Holding the SS at a hotel provided a neutral location for decision makers and scientists to come together. It is important for facilitators of synthesis sessions to keep the location as neutral as possible to avoid a perceived bias towards any particular sector and to promote open and honest communication.

\section{Conclusions}

Relevant research and evidence can ground and frame alternatives that arise in the policy and management process [18]. Coastal and marine human and ecological communities face pressures of climatic, demographic, and land use changes that require effective policy and management and the expertise of a wide range of scientists [16]. Connecting the decision making and scientific sectors in an iterative process can develop and infuse applied research into decisions [2]. Having the initial face-to-face workshop format allows for trust to be built [1] and new knowledge to be generated [18].

Here the research team has presented a case study SS to test this method of interaction and collaboration. Future workshops that attempt to connect the decision making and scientific communities to generate and obtain applied information for policy and management practices may find that a SS of this format, with the recommendations for improvements incorporated, can result in a high level of success. Workshops geared toward developing crosssector communication have the potential to infuse greater scientific data into the decision making process, resulting in more effective and efficient policy and management practices $[3,10]$. The SS conducted here revealed that getting practitioners from both sectors in a room together to interact freely can effectively initiate necessary conversation to remedy existing data gaps [18]. Opening these lines of communication through concentrated interactions brings relevant individuals together to realize their mutual interests and needs. By joining forces to address those interests and needs, professionals can co-produce scientific data that saves time and money for both sectors and has greater applicability to management and policy decisions [1,3,22].

To achieve these goals, both sectors must engage in follow-up to sustain the connections made at the workshop [20]. Sustaining connections requires post-event attention where participants can continue to discuss policy/management issues and applicable data as they arise. In a brief follow-up email survey, the participants of the SS indicated that a listserv was preferred over a blog for continued participation among this group. Researchers thus developed a listserv; however it has very low traffic. Booster workshops have also been noted to foster continued sector communication and information generation [19]. In general, sustaining long-term relationships of this nature will require additional research. It will be important to understand what drives scientists and decision makers to participate in cross-sector communication opportunities to inform design of effective mechanisms to sustain these relationships. Such long term success may take years to reach fruition and will take additional monitoring over time.

The SS, the novel approach designed and discussed here, was successful in the short term and has the potential to effectively address decision making questions by infusing applied scientific information into the process, as well as by making new or reinvigorating existing professional connections [10]. The SS offered a sounding board for intellectual pursuits to flow, and thus provides a real potential to make significant and lasting change [1] in marine and coastal resource management and other natural resource management domains, provided that scientists and managers continue to engage in knowledge generation and communication [22]. This format is intended to serve as a model for workshops across the country attempting to bring together scientists and decision makers with the goal of generating relevant scientific data and evidence-based decisions that meet coastal and marine management objectives more effectively under increasingly pressurized circumstances.

\section{Acknowledgements}

The research team thanks Oregon Sea Grant for its support of this project through the Robert E. Malouf Marine Studies Scholarship to KG. The research team also thanks all decision makers and scientists who participated in the workshop and helped propel evidence-based decision making forward. 
Appendix A. : Synthesis session agenda

Information Needs Assessment for

Coastal and Marine Management and Policy in the Pacific

Northwest (INACaMMP): Project:

Ecosystem services under changing climatic, land use and demographic conditions

INACAMMP CONFERENCE: REFLECTING ON SCIENTIFIC DATA NEEDS

FOR COASTAL AND MARINE NATURAL

RESOURCE MANAGEMENT

\section{Conference Agenda}

May 30th: 2014

10:00am-3:00pm

\begin{tabular}{|l|l|}
\hline Timeframe & Activity \\
\hline 10:00am-10:20am & $\begin{array}{l}\text { Registration, Pre-Event Survey, and Introduc- } \\
\text { tions (coffee provided) }\end{array}$ \\
\hline 10:20am-10:50am & $\begin{array}{l}\text { Presentation: Ecosystem Services and Data } \\
\text { Gaps }\end{array}$ \\
\hline 10:50am-12:30pm & Participant Mini-presentations \\
\hline 12:30pm-12:45pm & Break and Lunch distribution (lunch provided) \\
\hline 12:45pm-1:15pm & $\begin{array}{l}\text { Lunch, Discussion: Opening Lines of Communi- } \\
\text { cation }\end{array}$ \\
\hline 1:15pm-2:15pm & Science-Management "Speed Dating" \\
\hline 2:15pm-2:45pm & Discussion: Sustaining Connections \\
\hline 2:45pm-3:00pm & Wrap Up, Post-Event Survey \\
\hline
\end{tabular}

Seg firtint $\quad$ P Portland State

On behalf of the INACaMMP Project team, thank you for attending.

Synthesis session agenda edits as suggested in the Recommendations for Future Synthesis Sessions:

\begin{tabular}{ll}
\hline Timeframe & Activity \\
\hline 9:00 am-9:20 am & Registration, Pre-Event Survey, and Introductions (coffee provided) \\
9:20 am-9:50 am & Presentation: Ecosystem Services and Data Gaps \\
9:50 am-10:50 am & Discussion: Defining Key Marine Ecosystem Services \\
10:50 am-12:30 pm & Participant Mini-presentations \\
12:30 pm-12:45 pm & Break and Lunch distribution (lunch provided) \\
12:45 pm-1:15 pm & Working Lunch; Discussion: Opening Lines of Communication Part 1: Identifying Challenges and Barriers \\
1:15 pm-1:45 pm & Discussion: Opening Lines of Communication Part 2: Overcoming Challenges and Barriers
\end{tabular}


1:45 pm-3:15 pm

3:15 pm-4:00 pm

4:00 pm-4:15 pm

$4: 15 \mathrm{pm}-4: 30 \mathrm{pm}$
Science-Management "Speed Dating"

Discussion: Sustaining Connections and Suggestions for this Group

Wrap Up

Post-Event Survey

Appendix B. : Pre-event survey of expectations

2014 INACaMMP Conference for Ecosystem Services and Scientific Data Needs Under Changing Climatic, Land Use, and Demographic Conditions PARTICIPANT PRE-CONFERENCE EXPECTATIONS

Gender:

Male

Female

Professional Role (circle all that apply): Scientific Researcher Policy Maker Manager

Geographic location of job post (circle one): Inland Coastal

What do you expect to gain from this event? (Choose all that apply):

A. Learn more about key marine and coastal ecosystem services

B. Learn more about pressing marine and coastal data needs

C. Make personal connections with decision makers

D. Make personal connections with researchers

E. Develop new collaborations or connections

F. Other:

With the goal of reducing data gaps in mind, what characteristics result in a successful professional connection with practitioners across sectors (i.e. scientific researchers and/or policy makers and/or managers)?

What would inspire you to follow up with a personal connection you make during this conference?

How do you hope today's event enhances your capacity to communicate with individuals in other sectors? 
Appendix C. : Post-event evaluation

2014 INACaMMP Conference for Ecosystem Services and Scientific Data Needs Under Changing Climatic, Land Use and Demographic Conditions PARTICIPANT CONFERENCE EVALUATION

Gender: Male Female

Professional Role (circle all that apply): Scientific Researcher Policy Maker Manager

Geographic location of job post (circle one): Inland Coastal

Which of the following accurately represents your experience today? (Choose all that apply):
A. Learned more about key marine and coastal ecosystem services
B. Learned more about pressing marine and coastal data needs
C. Made personal connections with decision makers
D. Made personal connections with researchers
E. Developed a new collaboration or connection
F. Other:

How many new professional connections have you made today with whom you expect to:

A. Follow up?

B. Plan research project(s)?

Roughly when do you plan to follow up with individuals with whom you have connected at this event?

Please rank the top 3 activities from today's event:

1.

2.

3.

What would you recommend be added to this type of event in the future?

Please list the one thing you would omit from future events of this nature:

Appendix D. : Post-event email questions

1. Have you had any further communications/collaborations result from conversations or connections made during the INACaMMP workshop? If so, how many and with whom.

2. Has any further work emerged? If so, what work/with whom? 


\section{References}

[1] C. Cairns, M. Harris, Local cross-sector partnerships: tackling the challenges collaboratively, Nonprofit Manag. Leadersh. 21 (3) (2011) 311-324, http://dx. doi.org/10.1002/nml.

[2] C.N. Cook, M.B. Mascia, M.W. Schwartz, H.P. Possingham, R.A. Fuller, Achieving conservation science that bridges the knowledge-action boundary, Conserv. Biol. 27 (4) (2013) 669-678.

[3] C. Cvitanovic, A.J. Hobday, L. van Kerkhoff, S.K. Wilson, K. Dobbs, N.A. Marshall, Improving knowledge exchange among scientists and decision makers to facilitate the adaptive governance of marine resources: a review of knowledge and research needs, Ocean Coast. Manag. 112 (2015) (2015) 25-35.

[4] E. Davis, C. Moseley, C. Olsen, J. Abrams, J. Creighton, Diversity and dynamism of fire science and user needs, J. For. 111 (2) (2013) 101-107.

[5] N. Denzin, Y. Lincoln (Eds.), The SAGE Handbook of Qualitative Research, 4th ed.,Sage Publications, Thousand Oaks, California, 2011.

[6] M. Dobbins, P. Rosenbaum, N. Plews, M. Law, A. Fysh, Information transfer: what do decision makers want and need from researchers? Implement. Sci. 2 (20) (2007) 1-12.

[7] J. Fazey, J. Ingram, J. Gregson, P. Lowe, S. Morton, C. Trevitt, Knowledge exchange: a review and research agenda for environmental management, Environ. Conserv. 40 (1) (2012) 19-36.

[8] K. Goldsmith, E. Granek, A. Lubitow, Information needs assessment for coastal and marine management and policy: ecosystem services under changing climatic, land use, and demographic conditions, Environ. Manag. (2015), http: //dx.doi.org/10.1007/s00267-015-0576-z.

[9] E. Granek, S. Polasky, C.V. Kappel, D.J. Reed, D.M. Stoms, E.W. Koch, C. J. Kennedy, L.A. Cramer, S.D. Hacker, E.B. Barbier, S. Aswani, M. Ruckelshaus, G. M.E. Perillo, B.R. Silliman, N. Muthiga, D. Bael, E. Wolanski, Ecosystem services as a common language for coastal ecosystem-based management, Conserv. Biol. 24 (1) (2009) 207-216, http://dx.doi.org/10.1111/j.1523-1739.2009.01355. $\mathrm{X}$.

[10] K. Grorud-Colvert, S.E. Lester, S. Airamé, E. Neeley, S.D. Gaines, S.A. Levin, Communicating marine reserve science to diverse audiences, Proc. Natl. Acad. Sci. USA 107 (43) (2010) 18306-18311.

[11] S.K. Jacobson, Communication Skills for Conservation Professionals, 2nd ed., Island Press, Washington D.C., 2009.

[12] R. Jandl, A. Borsdorf, G. Siegel, COST strategy workshop, Mt. Res. Dev. 28 (2) (2008) 172-173, http://dx.doi.org/10.1659/mrd.1017.

[13] L. Karrer, P. Beldia II, B. Dennison, A. Dominici, G. Dutra, C. English,
T. Gunawan, J. Hastings, L. Katz, R. Kelty, M. McField, E. Nunez, D. Obura, F. Ortiz, M. Quesada, L. Sivo, G. Stone, Science-to-Action Guidebook, Science and Knowledge Division, Conservation International, Arlington, Virginia, USA, 2011.

[14] D. Lach, A. Parker, M. Boesl, Assessing Regional Climate Needs, 2012, Pacific Northwest Climate Decision Support Consortium Corvallis, Oregon, USA.

[15] J.N. Lavis, D. Robertson, J.M. Woodside, C.B. McLeod, J. Abelson, How can research organizations more effectively transfer research knowledge to decision makers? Milbank Q. 81 (2) (2003) 221-248.

[16] C. Murcia, G. Kattan, Application of science to protected area management: overcoming the barriers, Ann. Mo. Bot. Gard. 96 (3) (2009) 508-520, http://dx. doi.org/10.3417/2008031.

[17] National Research Council, Using science as evidence in public policy. Committee on the Use of Social Science Knowledge in Public Policy, in: K. Prewitt, T.A. Schwandt, M.L. Straf (Eds.), Division of Behavioral and Social Sciences and Education, 2012, The National Academies Press Washington, D.C.

[18] S. Oreszczyn, S. Carr, Improving the link between policy research and practice: using a scenario workshop as a qualitative research tool in the case of genetically modified crops, Qual. Res. 8 (4) (2008) 473-497.

[19] K.A. Pituch, K.A. Lawson, R.E. Wilcox, J.H. Littlefield, J.D. Miller, C.K. Erickson, A multisite evaluation of a communication skills workshop for scientists, J. Teach. Addict. 4 (2) (2006) 1-22, http://dx.doi.org/10.1300/J188v04n02_01.

[20] R. Renner, F. Schneider, D. Hohenwallner, C. Kopeinig, S. Kruse, J. Lienert, S. Link, S. Muhar, Meeting the challenges of transdisciplinary knowledge production for sustainable water governance, Mt. Res. Dev. 33 (3) (2013) 234-247.

[21] J. Risien (Ed.), West Coast Regional Marine Research and Information Needs, 2009, Oregon Sea Grant ORESU-Q-09-001, Corvallis, Oregon, USA.

[22] A. Rowe, K. Lee, Linking Knowledge with Action: an Approach to Philanthropic Funding of Science for Conservation. A Report to the Conservation \& Science Program, David \& Lucile Packard Foundation, Los Altos, California, USA, 2012.

[23] D. Stone, Using knowledge: the dilemmas of 'Bridging Research and Policy', Comp.: J. Comp. Educ. 32 (3) (2002) 285-296, http://dx.doi.org/10.1080 0305792022000007454.

[24] L.A. Wainger, D.M. King, R.N. Mack, E.W. Price, T. Maslin, Can the concept of ecosystem services be practically applied to improve natural resource management decisions? Ecol. Econ. 69 (5) (2010) 978-987, http://dx.doi.org/ 10.1016/j.ecolecon.2009.12.011. 